\title{
COMPORTAMIENTO DE LOS MUROS DRAGADOS-PLASTBAU AL CALOR Y A LA VARIACION DE HUMEDAD Y TEMPERATURA
}

\author{
A. Ruiz Duerto, IETcc/CSIC \\ J. A. Comas Valenzuela, Dragados y Construcciones, S. A.
}

Dentro del concepto DURABILIDAD, el programa de investigación del sistema Dragados-Plastbau incluyó el análisis del comportamiento de las cáscaras de microhormigón de los muros, frente a la radiación de calor y a la variación de la humedad y temperatura.

Estos ensayos fueron realizados en las instalaciones que para tal fin tiene el Instituto Eduardo Torroja, empleándose como muestra muros de $1,20 \mathrm{~m}$ de ancho $\times 2,50 \mathrm{~m}$ de alto del tipo I con $2,5 \mathrm{~cm}$ de espesor de cáscaras.

El objetivo de los ensayos fue el determinar las deformaciones y fisuraciones que se producirian durante la ejecución de los mismos, asi como realizar una toma de datos sobre la corrosión de las armaduras en esas condiciones y que forman parte del estudio de durabilidad de las armaduras que figura en otro de los artículos.

Las muestras no se revistieron con pintura ni otro revestimiento, con objeto de no enmascarar los resultados.

Para la realización de estos ensayos se situó frente a una de las caras del panel una pantalla, especialmente diseñada para este tipo de ensayos, que permite radiar calor de una forma uniforme sobre el panel y rociarlo, también de manera uniforme, con agua fria (aproximadamente $110 \mathrm{C}$ ) a razón de 1 litro/ $\mathrm{m}^{2} \mathrm{~min}$.

El sistema cuenta con un programador de manera que los ciclos humedad-temperatura se realizan automáticamente sin necesidad de presencia humana.

La temperatura se midió merced a unos termopares sobre cuerpo negro conectados al registrador de deformaciones, disponiéndose la pantalla radiante a la distancia precisa para lograr la temperatura deseada.
En la otra cara del muro se dispusieron 6 comparadores, tal y como se indica en el esquema, a $30 \mathrm{~cm}$ de los bordes y en 3 diferentes alturas; 60 $\mathrm{cm}, 120 \mathrm{~cm}$ y $190 \mathrm{~cm}$ del suelo.

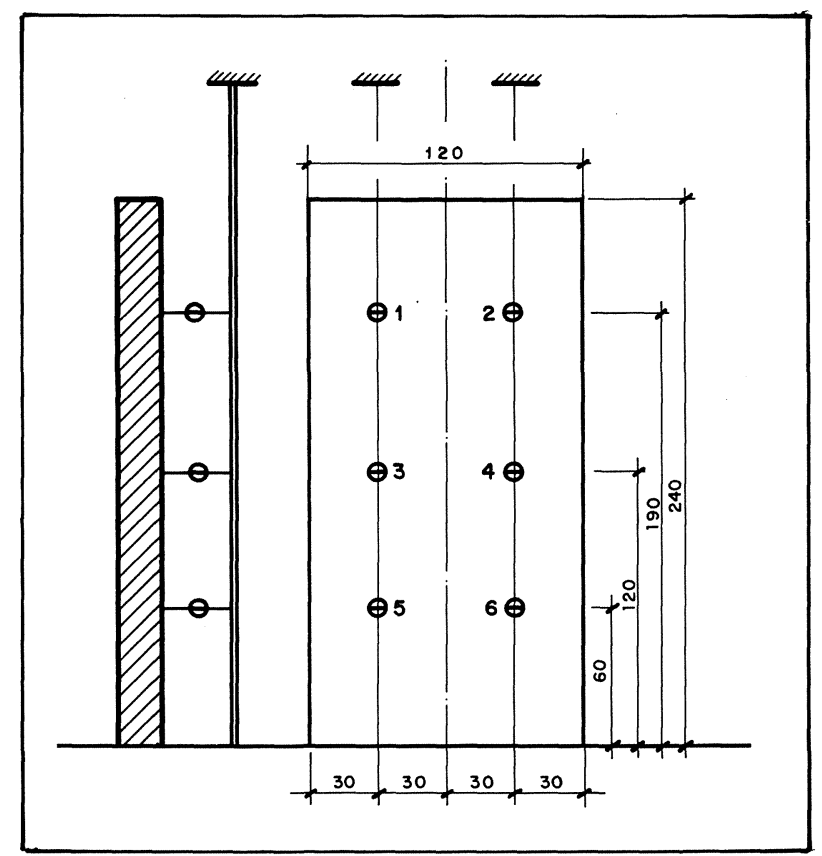

Se realizaron dos ensayos; en el primero el muro se encontraba anclado al suelo y techo mediante perfiles en $U$ de chapa galvanizada, fijados mediante disparos, rigidizándose los bordes libres por medio de dos redondos $\varnothing 10$ y una $U$ de malla, del mismo tipo que la empleada en los paneles, en cada uno de ellos.

El segundo ensayo se llevó a cabo con un muro sin ningún tipo de coacciones ya que no estaba anclado por ninguno de sus bordes. 
Los resultados de los ensayos fueron los siguientes:

\section{A) ENSAYO DE RADIACION DE CALOR}

Se estableció como temperatura de ensayo $60 \circ \mathrm{C}$, la cual se alcanzó en un tiempo aprox. de una hora manteniendo esta temperatura hasta la estabilización de las deformaciones.

En el primer ensayo la estabilización se logró a las 224 horas, mientras que en el segundo ésta se logró a las 240 horas.

En ambos se apreciaron pequeñas deformaciones, del orden de $1 \mathrm{~mm}$ en el primer caso y 1,80 $\mathrm{mm}$ en el segundo, con unas deformaciones residuales una vez dejado enfriar el muro 24 horas de $0,60 \mathrm{~mm}$ y $3,93 \mathrm{~mm}$ respectivamente. Los valores de las flechas residuales, correspondientes al segundo ensayo, no pueden considerarse significativas debido a que éste se realizó con el muro libre por tres de sus lados.

En cuanto a las fisuraciones, al final de los ensayos se pudieron apreciar en la cara delantera dos microfisuraciones horizontales coincidiendo con los alambres de la armadura. El ancho de las fisuras era del orden de 0,1 $\mathrm{mm}$.

\section{B) ENSAYO CICLICO DE VARIACION DE HUMEDAD Y TEMPERATURA}

Si bien no existe un ensayo especifico para muros de la constitución del PLASTBAU I por similitud de circunstancias, este ensayo se ha realizado siguiendo las "Directives UEAtc pour l'agrément des systemes d'isolation exterieure des facades avec enduit mince sur isolation".

Ha consistido en la realización de 140 ciclos sobre las muestras ensayadas frente a la radiación de calor. Cada ciclo comprendia:

- 3 horas de radiación a $70 \circ \mathrm{C}$,

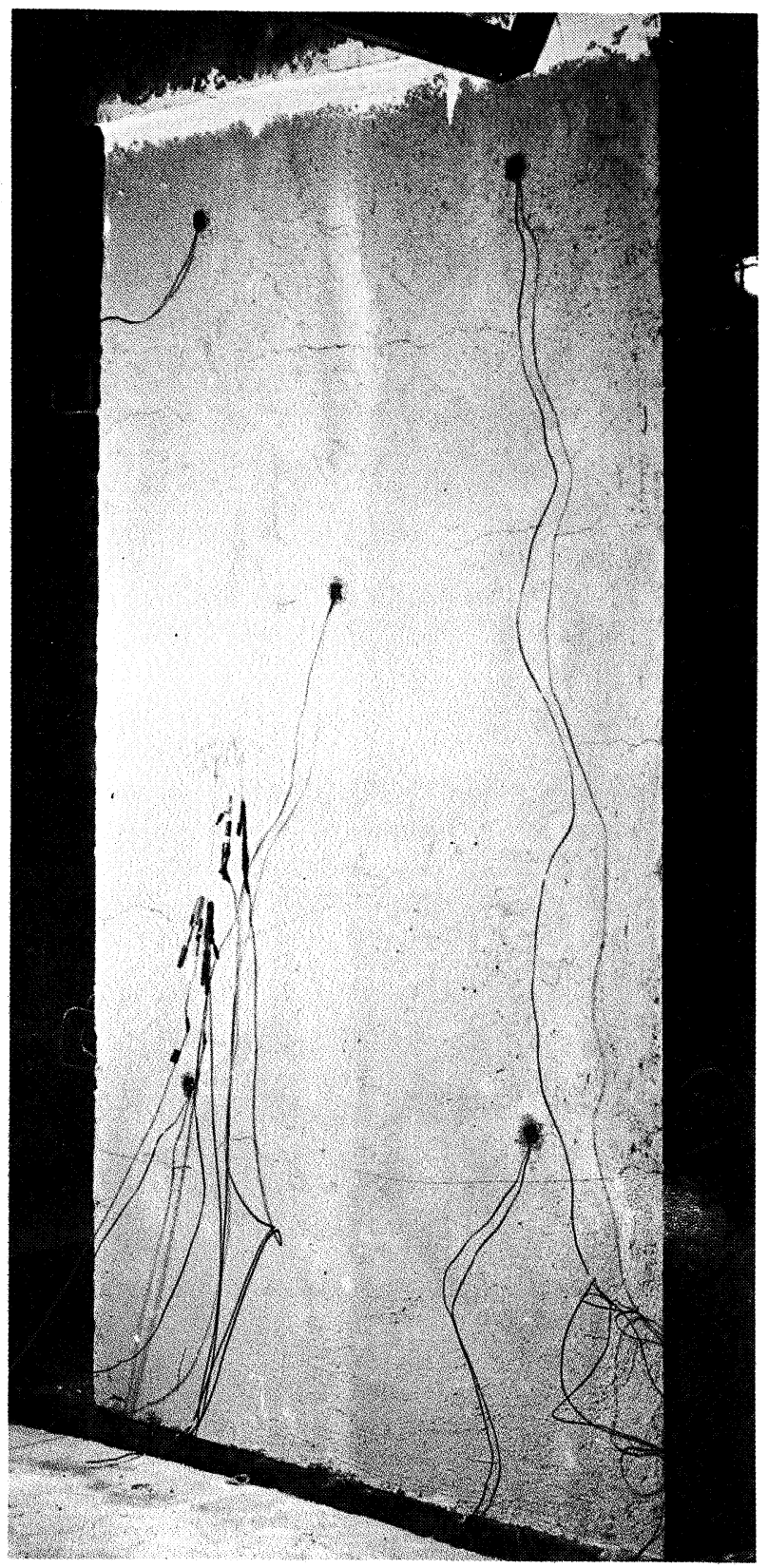

Fig. 1.

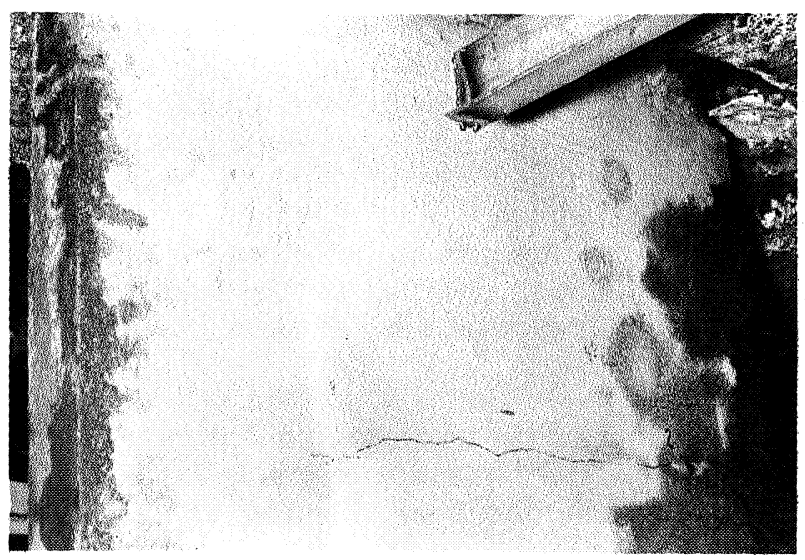

Fig. 2. 


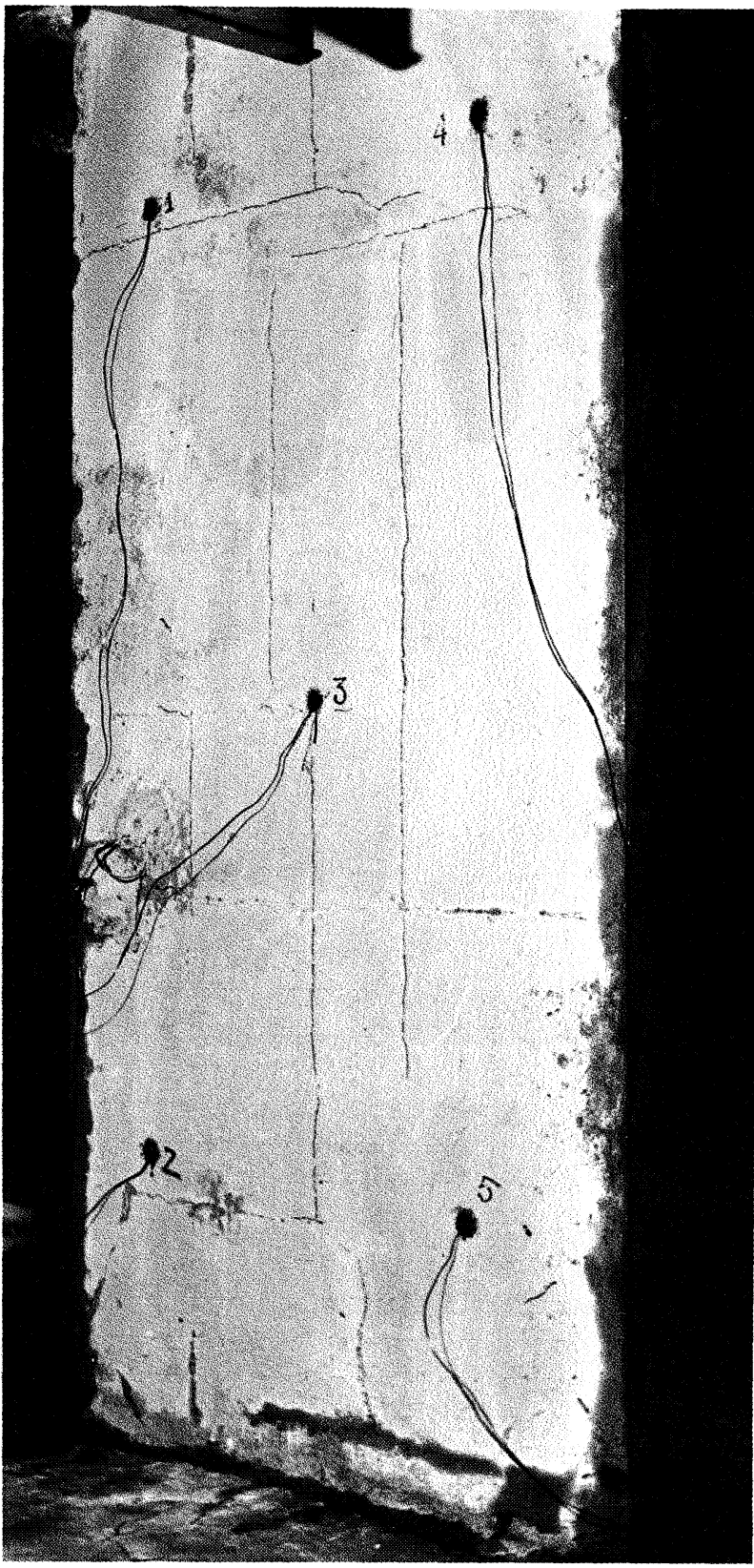

Fig. 3.

\section{- 3 horas de riego uniforme en las condiciones} antes indicadas.

En el primer ensayo (muro anclado) entre los ciclos 90 y 100 aparecieron una serie de microfisuras en la cara anterior del muro coincidentes con las armaduras del mallazo y en el trasdós apareció una microfisura horizontal. Entre los ciclos 100 y 140 aparecieron nuevas microfisuras siguiendo las armaduras de los mallazos ( 1 y 2 ).

En el segundo ensayo (muro libre) al finalizar el ciclo 16 aparecieron dos microfisuras verticales en el trasdós del muro. En la cara anterior aparecieron microfisuraciones horizontales, también coincidentes sensiblemente con las armaduras.
Al terminar el ciclo 76 las microfisuras verticales habian cubierto toda la altura del muro, apareciendo en la cara anterior nuevas microfisuras verticales (Fig. 3 ).

En este ensayo se apreciaron a partir del ciclo 16 unas humedades de tipo circular en la cara posterior coincidiendo con los extremos de los conectores que se convirtieron en abolsamientos y fisuraciones perimetrales alrededor del conector.

Se pudo comprobar al terminar el ensayo que las zonas de conectores afectadas no tenian los recubrimientos mínimos previstos.

\section{CONCLUSIONES}

La presencia del mallazo como armadura de los revestimientos resulta obligada, aparte las de resistencia mecánica, por la resistencia a la fisuración.

Esta solución hace que sin ningún tipo de revestimiento no pueda garantizarse la no aparición de pequeñas fisuras $(0,1 \mathrm{~mm})$ en el microhormigón, probablemente no generalizadas, siguiendo preferentemente la línea de los alambres.

En razón por un lado a la anchura de las fisuras producidas y por otra parte al diámetro de las armaduras, las eventuales consecuencias de la acción agua/calor que puedan producirse deben afectar, a la larga, más al aspecto que a la durabilidad intrínseca del microhormigón.

La solución propuesta satisface la exigencia de durabilidad con un margen de seguridad razonable, siempre que el recubrimiento de las armaduras sea el adecuado y se utilicen revestimientos que, además de aportar una cierta protección al soporte frente a la acción directa de los agentes externos de envejecimiento, sean capaces de puentear pequeñas fisuras del orden de 0,2 $\mathrm{mm}$. 